\title{
Sustainable road drainage Experimental model
}

\author{
Andung Yunianta ${ }^{1, *}$, Suripin ${ }^{1}$, and Bagus Hario Setiadji ${ }^{1}$ \\ ${ }^{1}$ Universitas Diponegoro, Civil Engineering Department, Semarang, Indonesia
}

\begin{abstract}
Roadway as part of land transportation is very important to actualize human or commodity movements. Roadway should be able to show good performance. It is known that inundation at roadway is very serious problem, and often causes disruption to road users. Conventional drainage system that has been applied with the concept of discharging or draining water to the drainage channel has not been able to evade rain water that falls on the road surface. To date, the load of drainage channel is increasing. This is contributed by the decrease of the drainage function in order to flow water through the channel. To overcome the problem, a new concept of eco-drainage, that is a concept to minimize the change of water discharge and pollutant as an impact of region development, is introduced. To do so, an experimental method with laboratory test of aggregate and soil will be conducted, followed by developing a roadway drainage model. This study aims to develop a sustainable road drainage system by increasing the ability of the drainage system in infiltrating water that related to road construction to soil in the means of providing artificial facilities. This artificial facility includes side channels, filter layers and infiltration wells. At the end of this study, the expected result is the ability to measure the efficiency and effectiveness of the performance of the model.
\end{abstract}

\section{Introduction}

Roadway represents an infrastructure that functions as media of land transportation movement, either motorized or non-motorized vehicles, and also pedestrian. The roadway infrastructure is generally designed to be able to cater the vehicle movements for certain design period by considering various factors, such as construction material, and also the number of vehicle load repetition that will work on it.

In service period, beside vehicle load repetition, natural factor in the form of rainfall can cause the presence of surface water run-off on roadway and the surrounding unpaved parts. The road surface will increase waterproof surfaces, therefore, high rainfall can increase the volume of surface water run-off volume and as a result, inundation on roadway surface might be occurred if road drainage does not function well. This can be contributed by waste, such as organic waste (leave, plants, and so on), and in-organic waste produced by

* Corresponding author: Andung.ay@gmail.com 
human, causing to heap or fulfill road drainage channel. Therefore, it could cork the road drainage channel and result overflow water when it rain is fall. This all happen due to the understanding that surface run-off has to discharge immediately through drainage channel. If something occurs on the channel, it is the beginning of the continuous destruction of the road.

One solution offered is what people called as Sustainable Urban Drainage Systems (SUDS) i.e. a system which consists of one or more structures developed to manage surface water run-off [1]. The basic concept of this system is to improve water usefulness, to minimize the loss, and also to improve environmental conservation [2]. One of the efforts is to detain or reduce the speed of the surface water run-off when rainfall and immediately infiltrate the water into soil. As a whole, SUDS can be categories into several rainfall retention facilities, as seen in Figure 1.

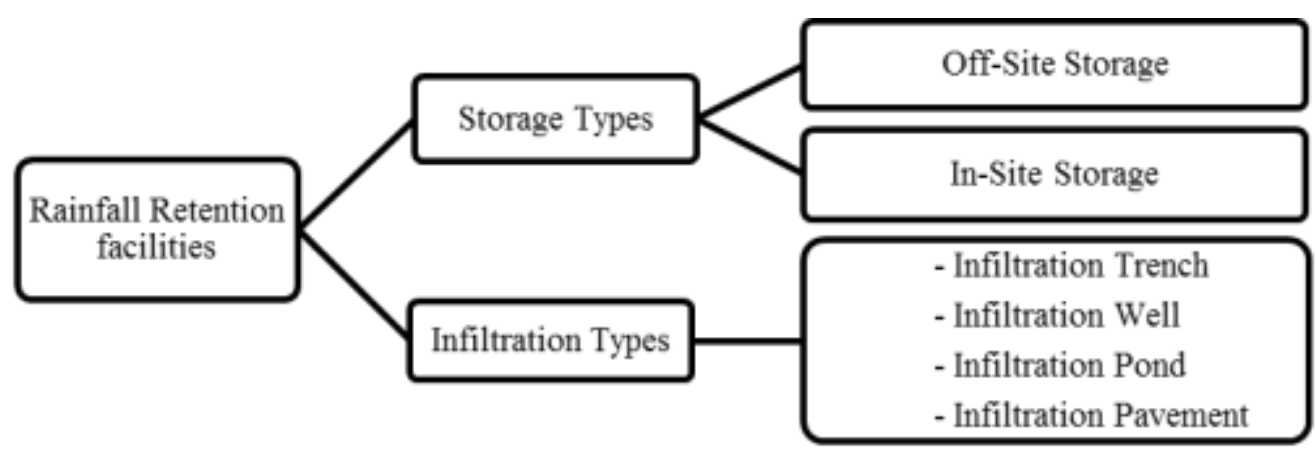

Fig. 1 Classification of Rainfall Retention Facilities in SUDS.

This aim of this research is to propose a design of sustainable road drainage system, in means of three facilities (side channel, filter layer and infiltration well), to overcome especially water inundation problem that is suitable for Indonesia condition. This paper is a documentation of the proposed of experimental model of a design of sustainable road drainage system, that is still in the development stage of the structure of the infiltration well.

\section{Sustainable road drainage system concept}

To date, the concept of drainage system has developed broadly into a concept of integrated water management which tends to detain rainwater in the place it falls. One concept is known as Low Impact Development (LID), that is, an environmental-friendly drainage systems concept that maintains the natural and hydrology conditions like the condition early before development. It is a concept to maintain and also imitate existing natural process to minimize the change of water discharge and pollutant as an impact of region development.

This environment-friendly drainage system is defined as an effort to manage excess water by infiltrating naturally as much as possible water into soil or flowing the water to river without exceed previous river capacities. There are several factors required to be evaluated in this concept, which cover proposed road drainage system, hydrology and hydraulics, soil permeability, infiltrate, aggregate gradation selection, and infiltration well. 


\subsection{Road drainage}

According to new Indonesia Road Design Guide, in planning road drainage system, it should consider the existence of surface and sub-surface water, so that the proposed road drainage system can be divided into surface drainage system and sub-surface drainage system [3].

In general, to design road drainage system, it is commenced by plotting the evaluated road route onto topography map to know the service area so that it can be predicted the location required for drainage structures (drainage channel, infiltration well, and so on). In the design, it should consider surface or sub-surface water flow by following the design guide without disturbing the road construction stability.

\subsection{Hydrology and hydraulics}

In hydrology, one should concern about the water resources, the potency of floods, the cycles of the water process (evaporation, precipitation, infiltrate and out flow). On the other hand, people learn about the structure required to transport the water in hydraulics. It can be opened or closed channel and factors that affect the selection between them. The interaction between hydrology and hydraulics will enable to provide effective and efficient drainage system.

\subsection{Soil permeability}

Permeability is defined as a characteristic of pore materials that enable water to pass pore cavity. Soil pore interact each other so that water can flow from one point with high energy to another point with low energy. In the soil, the possible water stream could be laminar or turbulent. The restraint of the water flow could be contributed by soil type, granular size and shape, mass density, and also the geometry form of pore cavity. Temperature is also very influence to water restraint (surface tension and viscosity).

\subsection{Infiltration}

Infiltration is the flow of water into the soil through the soil surface. In the ground, water flows in lateral direction, as inter-flow to the spring, river or lake. It can also flow in the ground vertically, known by percolation. The movement of water in the soil through the pores of the soil is affected by the force of gravity and capillary force. The force of gravity causes the flow always go to the lower places, while the capillary force causes the water to move in all directions. Capillary water is always moving from the wet to dry areas. Dry soil has a larger capillary force than wet soil. This force decreases with the increase of soil moisture. In addition, the capillary force works stronger on the ground with fine grains of clay rather than coarse grained soil such as sand.

\subsection{Aggregate and aggregate gradation selection}

Aggregates are commonly defined as hard rock formations of the earth and shafts. ASTM 1974) defining aggregate as a material which consist of solid mineral, in the form of a large size and/or fragments. Beside aggregate properties, aggregate gradation becomes one important factor in filter layer consisted of aggregates. This is because it could affect the ability of the filter layer (in terms of velocity and volume) to flow in the water. 


\subsection{Infiltration well}

Infiltration well is one of technical water conservation in the form of well with selected depth, filled with infiltration materials (such as sand, stone, fibre of palmtree) layer by layer up to it reaches same level with surface, in which it functions as relocation place and at the same time as a place where water infiltrate into soil [4].

\section{Thinking framework and research methodology}

The thinking framework of this research can be illustrated in the flow chart as shown in Figure 2 .

\section{Phenomenon encountered}

1. The presence of roadway reduce open space for water infiltration to soil

2. The occurrence of inundation and surface run-off on the roadway due to rainfall.

3. The failure of the function of drainage system.

4. Pavement damage due to inundation

5. Waste disposal that covers drainage channel.

\section{Critical Review from} Publications

1. Reducing inundation by optimizing existing drainage system and removing sedimentation [5]

2. Optimization of crosssectional area of drainage channel as a solution to the problem of channel insufficiency in collecting water discharge [6]

3. Inundation affects mostly on aggregate material of surface layer, but affects less on asphalt content [7].

4. Hydrology and water quality aspects of filter drain materials of road drainage in controlling surface run-off [8].

5. Drainage system with infiltration well to reduce rainfall volume [9]
Proposed Research Main Idea

Sustainable Road Drainaqe

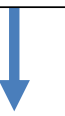

\section{Research Objective}

To obtain a sustainable road drainage model to address existing drainage system problems.

1. Model development

2. Data collection

3. Laboratory tests

4. Data compilation and analysis

5. Model test at field
Critical Review from Standards Used

1. Open channel drainage system to flow rain water to water body (Road drainage system design guide No. 008/T/BNKT/1990 and Pd T-02-2006-B)

2. Environmental-friendly drainage system or Ecodrainage (Regulation of Ministry of Public Works No. 12/PRT/M/2014) [10]

3. Maintenance of roadway (includes road drainage system) to ensure smooth passenger and freight movement and sustainable economic growth (Road pavement design manual No. 02/M/BM/2013).

Fig. 2 Thinking framework of the research 
According to Figure 2, the research methodology of this research is as follows.

\subsection{Model development}

In this research, the model of sustainable road drainage system is as illustrated in Figure 3. The model of sustainable road drainage system is developed using the following criteria:

\subsubsection{Drainage roadway channel}

a. The channel has a trapezium form and made of pairs of aggregate with mortar or concret;

b. The floor of the channel is not hardened at certain location to enable water infiltrates to soil.

c. At the point of channel wall near infiltration well, inlet pipe is installed integrated to infiltration well, attached above and under channel wall

d. Aggregate (that pass all laboratory tests) is placed as filter in the channel.

\subsubsection{Infiltration well}

a. Infiltration well is made of concrete buis with $1-\mathrm{m}$ diameter

b. The depth of infiltration well is influenced by the depth of ground water surface, i.e. shallow infiltration well if ground water surface is deep or a deep infiltration well if ground water surface is shallow.

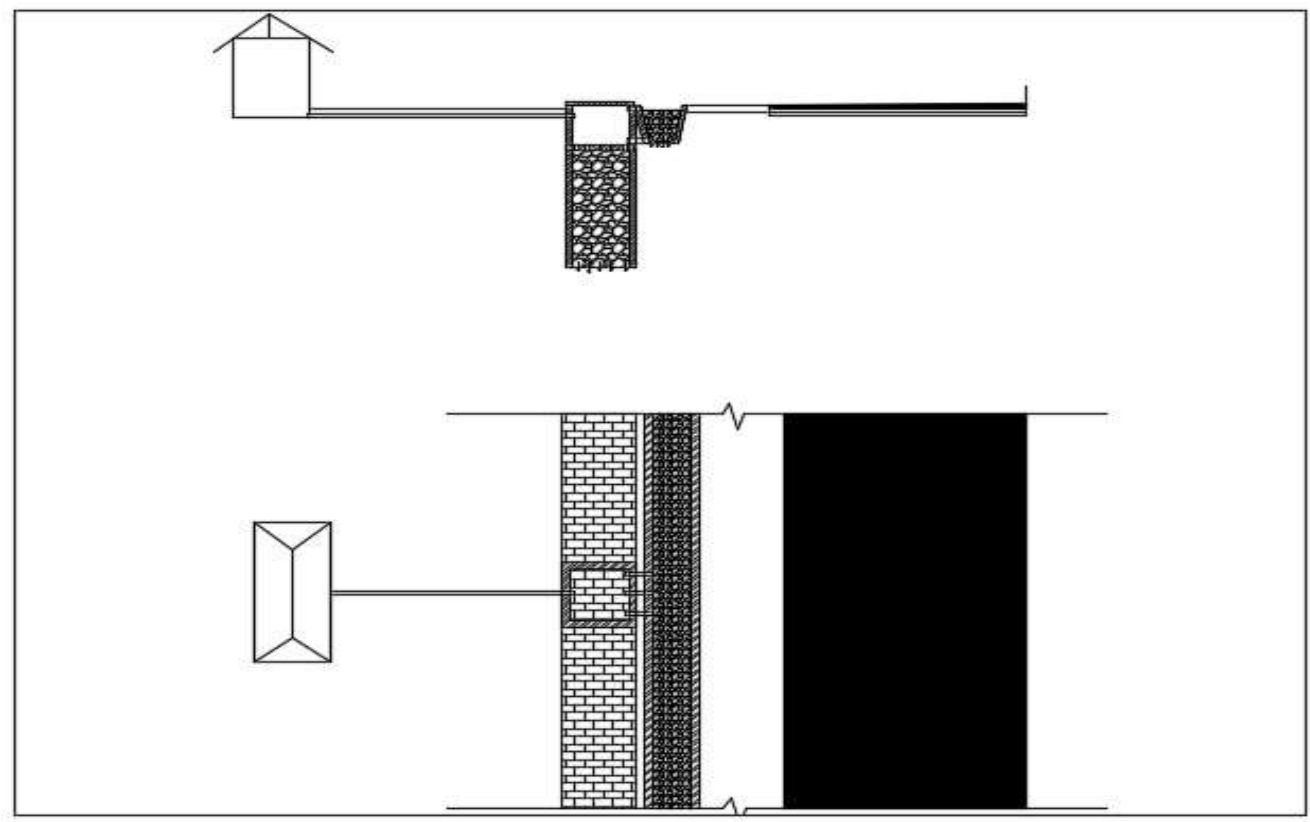

Fig. 3 Proposed Road Drainage System Model

This research is a quantitative type that used to research on a population or specific samples. Data collection is conducted by using research instruments, and analysis is conducted quantitatively/statistically with the aim to test the predefined hypothesis [5]. 
Table 1 Dependent and Independent Variables

\begin{tabular}{|l|l|}
\hline \multicolumn{1}{|c|}{ Dependent Variable } & \multicolumn{1}{c|}{ Independent Variable } \\
\hline Rainfall & Hydrology analysis \\
\hline Run-off debit & Run-off flow \\
\hline Channel dimension & Hydraulic analysis \\
\hline Permeability level & Soil permeability \\
\hline Aggregate gradation & Aggregate selection \\
\hline Depth of infiltration well & Level of ground water surface \\
\hline
\end{tabular}

There are several independent variables and their corresponding dependent variables used in this research (see Table 1). The values of both variables were observed and measured, to understand the correlation and the effect of each independent variable to its corresponding dependent variable, and vice versa.

\subsection{Data collection}

There are two types of data collection that are proposed to be performed. They are:

1. Primary data, which consists of:

a. measurement of existing drainage channel dimension and velocity of the water flow,

b. documentation of existing drainage system condition and the surroundings

c. interview to related stakeholders (highway authority, academics, and so on).

2. Secondary data, which consists of collection of several recorded data as follows.
a. rainfall data
b. area of evaluated region
c. slope of existing channel
d. number of population of evaluated region
e. topography of evaluated region

\subsection{Laboratory Test}

There are several laboratory tests will be performed in the next future. They are: (i) aggregate test, (ii) soil permeability test, and (iii) test of road drainage system model.

The aggregate tests aim to know the aggregate quality used for filter at drainage system. The aggregate tests consist of several tests as follows.

1. Sieve analyse, that is conducted to determine the gradation of the aggregate. Different aggregate gradation will be used in the test of road drainage system model to simulate the best aggregate gradation used as filter in drainage system.

2. Specific gravity and absorbtion of coarse aggregate. This test is to determine the specific gravity of aggregate (bulk, saturated surface dry/SSD and apparent), and also to know level absorption of aggregate.

3. Flakiness and elongation index, this test is used to limit the number of thin and long aggregate used in the proposed aggregate gradation.

4. Los Angeles aggregate abrasion test, to minimize the number of aggregate that tend to crushing, degradation and disintegration due to abrasion and impact force.

In soil permeability test in laboratory, there are four different tests to determine coefficient permeability of the soils [6] as follows:

1. Constant head permeabiltas test 
2. Falling head permeability test

3. Determination of permeability coefficient using consolidation test.

4. Capillary horizontal test.

Test of road drainage system model aims to measure the level of water infiltration. To do so, models of road drainage system with aggregate as filter are prepared in laboratory. A simulation will be conducted by using different aggregate gradations as filler to determine the suitable aggregate gradation used with different slopes of the channel and also different amount of surface run-off. The test is carried out by measuring several parameters regarding to the performance of the model, such as time of water infiltration, the presence of inundation on top of drainage channel, the quality of water obtained from the outlet of infiltration well, and so on. It is expected that different model can be developed based on different condition encountered in the field. The illustration of typical cross-section of the model is as depicted in Figure 4.

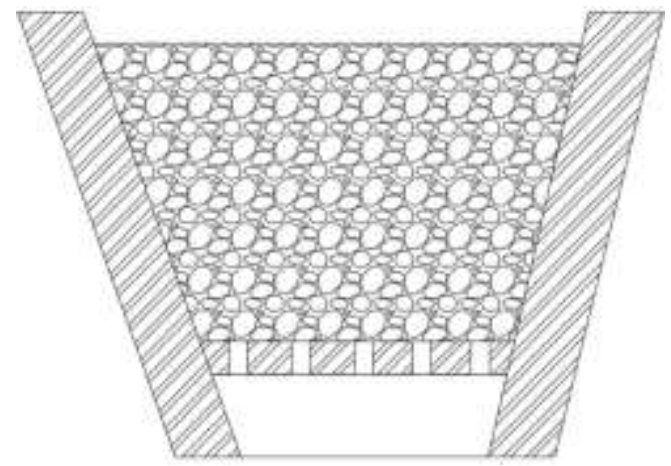

Fig. 4. Typical Cross Section of Road Drainage System Model with Aggregate as Filter

\subsection{Evaluation and Validation Model}

To evaluate the performance of the model, it is necessary to conduct validation process by applying and examining all components of the proposed drainage system, i.e. side channel, filter layers and infiltration well, at different conditions that commonly encountered at the field. Validation process is especially conducted to evaluate the level of water infiltration in the aggregate filter and also the velocity of water flow in the infiltration well. This step represents the period to find out the backwards of the proposed model for future development.

\section{Conclusion}

This paper proposed a new concept of environmental-friendly or sustainable road drainage system in which the surface water run-off is infiltrated through an integrated artificial facility consisted of side channels, filter layers and infiltration wells, instead of discharging it through side channel into water body. This new concept is also to be able to minimize the change of water discharge and pollutant as an impact of roadway operational and maintenance work. It is expected that the proposed integrated artificial facility can help the roadway free of problems due to moisture, such as inundation and flooding. 


\section{Reference}

1. Estonia Latvia Programme, Handbook on Sustainable Urban Drainage Systems, European Union. (2013).

2. Suripin, Sustainable Urban Drainage System, Andi Publisher, Yogyakarta, Indonesia (in Bahasa Indonesia). (2004).

3. Ministry of Public Works, Road Drainage System Design Guide, Pd.T-02-2006-B (in Bahasa Indonesia). (2006).

4. Kusnaedi, Infiltration Well for Urban and Rural Settlements. PT. Penebar Swadaya, Jakarta, Indonesia (in Bahasa Indonesia). (2002).

5. Liany, A.H, Optimization of Road Drainage System as an Alternative Solution to Inundation, Journal Tekno Sipil, Vol.12 No.16, Sam Ratulangi University, Manado, Indonesia (in Bahasa Indonesia). (2014).

6. Syapawi, A. Study of Drainage and Flood Water Inundation Problems on Jalan Kemang Manis, Journal Pilar Teknik Sipil, Polsri, Palembang, Indonesia (in Bahasa Indonesia). (2014).

7. Chairuddin, F, Experimental Assessment of the Impact of Rainwater Inundation on Asphalt Pavement Structures (Case Study Dr. Wahidin Sudiro Husodo Street, Makassar City), Proceedings of KonTeks 7, Sebelas Maret University, Surakarta, Indonesia (in Bahasa Indonesia). (2013).

8. Nursetiawan, Performance Review of Drain Filters on Highway as One Kind of Sustainable Drainage System Forms, Institut Teknologi Nasional, Bandung, Indonesia (in Bahasa Indonesia). (2006).

9. Mahardika, A.R, Yulianto, F.A, Suripin, and Budieny, H., Design of Environmental friendly Drainage System on Semarang - Solo Toll Road, Undergraduate thesis, Departement of Civil Engineering, Faculty of Engineering, Diponegoro University, Semarang, Indonesia (in Bahasa Indonesia). (2015).

10. Ministry of Public Works, Regulation of Ministry of Public Works No. 12/PRT/M/2014 (in Bahasa Indonesia). (2014). 